\title{
Mixed-Mode Delamination Failure Model of Sandwich Plate
}

\author{
Eva Kormanikova ${ }^{1}$ \\ ${ }^{1}$ Institute of Structural Engineering, Civil Engineering Faculty, Technical University of Košice
}

\begin{abstract}
Plane fracture of two plies is defined as delamination that can be found between plies in a laminate or sandwich structure. The interface model is solved using fracture and contact mechanics. Within the standard First-Order Deformation Theory of laminates, the mixed-mode delamination failure model is solved. The damage propagation parameters are calculated using the ANSYS code. The delamination problem is solved in a numerical example.
\end{abstract}

Keywords - Core, delamination, facesheet, finite element analysis, interface, sandwich, plate.

\section{INTRODUCTION}

Composite materials have various types of applications in many areas of engineering. The introduction of sandwich structures is made in a variety of naval engineering applications.

One can investigate an initiation and propagation of delamination. Most analyses evaluate the energy release rate (ERR). By [1], variational methods were used for evaluation of ERR. The ERR approach was later extended by [2].

In a layered structure, generally, first and second interface failure modes are observed. The first mode involves opening mode or delamination buckling, the second one is shearing mode.

\section{PERIODIC MicRostruCture MODEL}

Assume a sandwich made of fiber-reinforced outer layers with random distribution of fibers. A random microstructure is well-approximated by a periodic microstructure model (Fig. 1).

In general, there is a correlation between stress, strain, stiffness and the position inside the representative volume element (RVE) [3]-[8].

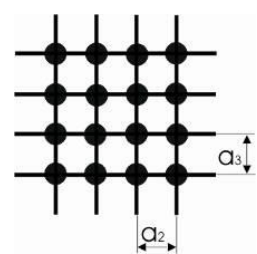

Fig. 1. Periodic microstructure model.

The elastic properties of a homogenized material can be computed by [3]:

$$
\begin{gathered}
E_{11}=\lambda^{(\mathrm{m})}+2 \mu^{(\mathrm{m})}-\frac{\xi^{(\mathrm{f})}}{D}\left(\begin{array}{l}
\frac{S_{3}^{2}}{\mu^{(\mathrm{m}) 2}}-\frac{2 S_{6} S_{3}}{\mu^{(\mathrm{m}) 2} g}-\frac{a S_{3}}{\mu^{(\mathrm{m})} c}+\frac{S_{6}^{2}-S_{7}^{2}}{\mu^{(\mathrm{m}) 2} g^{2}}+ \\
+\frac{a S_{6}+b S_{7}}{\mu^{(\mathrm{m})} g c}+\frac{a^{2}-b^{2}}{4 c^{2}}
\end{array}\right) \\
E_{12}=\lambda^{(\mathrm{m})}+\frac{\xi^{(\mathrm{f})}}{D} b\left(\frac{S_{3}}{2 c \mu^{(\mathrm{m})}}-\frac{S_{6}-S_{7}}{2 c \mu^{(\mathrm{m})} g}-\frac{a+b}{4 c^{2}}\right) \\
E_{22}=\lambda^{(\mathrm{m})}+2 \mu^{(\mathrm{m})}-\frac{\xi^{(\mathrm{f})}}{D}\left(-\frac{a S_{3}}{2 \mu^{(\mathrm{m})} c}+\frac{a S_{6}}{2 \mu^{(\mathrm{m})} g c}+\frac{a^{2}-b^{2}}{4 c^{2}}\right) \\
E_{66}=\mu^{(\mathrm{m})}-\xi^{(\mathrm{f})}\left(-\frac{S_{3}}{\mu^{(\mathrm{m})}}+\left(\mu^{(\mathrm{m})}-\mu^{(\mathrm{f}))^{-1}}\right)^{-1}\right. \\
E_{23}=\lambda^{(\mathrm{m})}+\frac{\xi^{(\mathrm{f})}}{D}\left(\frac{a S_{7}}{2 \mu^{(\mathrm{m})} g c}-\frac{b a+b^{2}}{4 c^{2}}\right) \\
E_{44}=\mu^{(\mathrm{m})}-\xi^{(\mathrm{f})}\left(-\frac{2 S_{3}}{\left.\mu^{(\mathrm{m})}+\left(\mu^{(\mathrm{m})}-\mu^{(\mathrm{f})}\right)^{-1}+\frac{4 S_{7}}{\mu^{(\mathrm{m})} g}\right)^{-1}},\right.
\end{gathered}
$$

where

$$
\begin{aligned}
& D=\frac{a S_{3}^{2}}{2 \mu^{(\mathrm{m}) 2} c}-\frac{a S_{6} S_{3}}{\mu^{(\mathrm{m}) 2} g c}+\frac{a\left(S_{6}^{2}-S_{7}^{2}\right)}{2 \mu^{(\mathrm{m}) 2} g^{2} c}+\frac{S_{3}\left(b^{2}-a^{2}\right)}{2 \mu^{(\mathrm{m})} c^{2}}+ \\
& +\frac{S_{6}\left(a^{2}-b^{2}\right)+S_{7}\left(a b+b^{2}\right)}{2 \mu^{(\mathrm{m})} g c^{2}}+\frac{\left(a^{3}-2 b^{3}-3 a b^{2}\right)}{8 c^{3}}
\end{aligned}
$$

and

$$
\begin{gathered}
a=\mu^{(\mathrm{f})}-\mu^{(\mathrm{m})}-2 \mu^{(\mathrm{f})} \boldsymbol{v}^{(\mathrm{m})}+2 \mu^{(\mathrm{m})} \boldsymbol{v}^{(\mathrm{f})} \\
b=-\mu^{(\mathrm{m})} \boldsymbol{v}^{(\mathrm{m})}+\mu^{(\mathrm{f})} \boldsymbol{v}^{(\mathrm{f})}+2 \mu^{(\mathrm{m})} \boldsymbol{v}^{(\mathrm{m})} \boldsymbol{v}^{(\mathrm{f})}-2 \mu^{(\mathrm{f})} \boldsymbol{v}^{(\mathrm{f})} \boldsymbol{v}^{(\mathrm{m})} \\
c=\left(\mu^{(\mathrm{m})}-\mu^{(\mathrm{f})}\right)\left(\begin{array}{c}
\mu^{(\mathrm{f})}-\mu^{(\mathrm{m})}+\mu^{(\mathrm{f})} v^{(\mathrm{f})}-\mu^{(\mathrm{m})} v^{(\mathrm{m})}+2 \mu^{(\mathrm{m})} v^{(\mathrm{f})}- \\
-2 \mu^{(\mathrm{f})} v^{(\mathrm{m})}+2 \mu^{(\mathrm{m})} v^{(\mathrm{f})} v^{(\mathrm{m})}-2 \mu^{(\mathrm{f})} v^{(\mathrm{m})} v^{(\mathrm{f})}
\end{array}\right) \\
g=\left(2-2 v^{(\mathrm{m})}\right) \\
\lambda=\frac{E}{(1+v)(1-2 v)} \\
\mu=G=\frac{E}{2(1+v)} .
\end{gathered}
$$


The constants $S_{3}, S_{6}$, and $S_{7}$ can be approximated [3]:

$$
\begin{aligned}
& S_{3}=0.49247-0.47603 \xi^{(\mathrm{f})}-0.02748 \xi^{(\mathrm{f}) 2} \\
& S_{6}=0.36844-0.14944 \xi^{(\mathrm{f})}-0.27152 \xi^{(\mathrm{f}) 2} \\
& S_{7}=0.12346-0.32035 \xi^{(\mathrm{f})}+0.3517 \xi^{(\mathrm{f}) 2} .
\end{aligned}
$$

When the components of elastic matrix $E$ can be derived, the material characteristics needed for modeling at macroscopic level can be calculated:

$$
\begin{gathered}
E_{1}=E_{11}-\frac{2 E_{12}^{2}}{E_{22}+E_{23}} \\
E_{2}=\frac{\left(2 E_{11} E_{22}+2 E_{11} E_{23}-4 E_{12}^{2}\right)\left(E_{22}-E_{23}+2 E_{44}\right)}{3 E_{11} E_{22}+E_{11} E_{23}+2 E_{11} E_{44}-4 E_{12}^{2}} \\
G_{12}=E_{66} \\
v_{12}=\frac{E_{12}}{E_{22}+E_{23}} .
\end{gathered}
$$

\section{STRESS RESULTANTS AND STRESS ANALYSIS OF} SANDWICHES

The in-plane forces, moments and transverse shear forces are defined by:

$$
\begin{gathered}
N=\int_{-\left(\frac{1}{2} h_{2}+h_{1}\right)}^{-\frac{1}{2} h_{2}} \sigma d z+\int_{\frac{1}{2} h_{2}}^{\frac{1}{2} h_{2}+h_{3}} \sigma d z \\
M=\int_{-\left(\frac{1}{2} h_{2}+h_{1}\right)}^{-\frac{1}{2} h_{2}} \int_{\frac{1}{2} h_{2}}^{\frac{1}{2} h_{2}+h_{3}} \\
V=\int_{-\frac{1}{2} h_{2}}^{\frac{1}{2} h_{2}} .
\end{gathered}
$$

For the resultants $N$ and $M$, the integration is carried out over the sheets $\left(h_{1}, h_{3}\right)$ only and for the transverse shear force $V$ over the core $\left(h_{2}\right)$ [9]-[12].

The constitutive equation in hypermatrix form is written as [9]:

$$
\left(\begin{array}{l}
N \\
M \\
V
\end{array}\right)=\left(\begin{array}{ccc}
A & B & 0 \\
C & D & 0 \\
0 & 0 & \bar{A}
\end{array}\right)\left(\begin{array}{l}
\bar{\varepsilon} \\
k \\
\gamma
\end{array}\right)
$$

where $\varepsilon$ is the membrane strain vector, $k$ is the curvature, and $\gamma$ is the transverse shear strain.

The stiffness coefficients are defined by:

$$
A_{i j}=A_{i j}^{(1)}+A_{i j}^{(3)}
$$

$$
\begin{gathered}
B_{i j}=\frac{1}{2} h_{2}\left(A_{i j}^{(3)}-A_{i j}^{(1)}\right) \\
C_{i j}=C_{i j}^{(1)}+C_{i j}^{(3)} \\
D_{i j}=\frac{1}{2} h_{2}\left(C_{i j}^{(3)}-C_{i j}^{(1)}\right),
\end{gathered}
$$

where

$$
\begin{gathered}
A_{i j}^{(1)}=\int_{-\left(\frac{1}{2} h_{2}+h_{1}\right)}^{-\frac{1}{2} h_{2}} E_{i j} d z=\sum_{k=1}^{n_{1}}{ }^{k} E_{i j}{ }^{k} h \\
A_{i j}^{(3)}=\int_{C_{i j}}^{\frac{1}{2} h_{2}+h_{3}} E_{i j} d z=\sum_{k=1}^{n_{2}}{ }^{k} E_{i j}{ }^{k} h \\
C^{(1)}=\int_{-\left(\frac{1}{2} h_{2}+h_{1}\right)}^{-\frac{1}{2} h_{2}} E_{i j} z d z=\sum_{k=1}^{n_{1}}{ }^{k} E_{i j}{ }^{k} h^{k} \bar{z} \\
C_{i j}^{(3)}=\int_{\frac{1}{2} h_{2}+h_{3}} E_{i j} z d z=\sum_{k=1}^{n_{2}}{ }^{k} E_{i j}{ }^{k} h^{k} \bar{z} \\
\bar{A}_{i j}=E_{i j}{ }^{t} h_{2} \quad,
\end{gathered}
$$

where $n_{1}$ and $n_{2}$ are the numbers of layers in the lower and the upper sheet, respectively, $E_{i j}$ are the in-plane elastic moduli of the sheets, and $E_{i j}^{t}$ are the transverse shear moduli of the core.

\section{THEORY OF FAILURE IN A LAYERED STRUCTURE}

One of delamination configurations which have been investigated in literature is the beam-type delaminated specimen subjected to bending, axial, and shear loading. It forms the basis for experimental methods used to measure interlaminar fracture strength under pure mode I, mode II, mode III, and mixed-mode conditions in composites, adhesive joints, and other laminated materials. Individual modes of fracture are illustrated in Fig. 2.
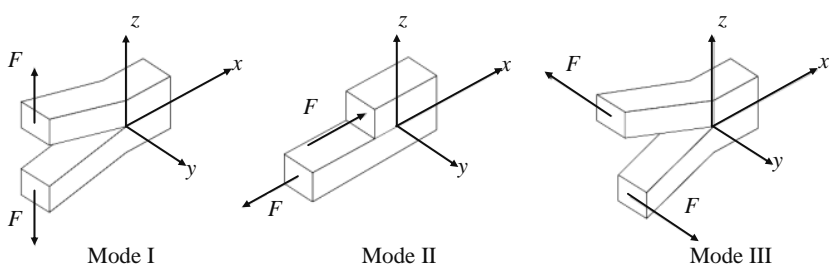

Fig. 2. Fracture modes of delamination growth: Mode I - opening, Mode II sliding, Mode III - tearing.

The mechanisms that lead to failure in composite materials are not fully understood yet, especially for matrix or fiber compression. Strength-based failure criteria are commonly 
used by FEM to predict failure events in composite structures. Different continuum-based criteria have been derived to relate the internal stresses and experimental measures of material strength to the onset of failure [13]-[16]. In Fig. 3, a laminate contains a single in-plane delamination crack of area $\Omega_{D}$ with a smooth front $\partial \Omega_{D}$. The laminate thickness is denoted by $h_{0}$. In this case, each sublaminate is represented by an assemblage of the first-order shear deformable (FSDT) plate elements bonded by zero-thickness interfaces in the transverse direction as shown in Fig. 4. Accordingly, the displacements in the $z$-th plate element, in terms of a global reference system located at the laminate mid-surface, are expressed [3], [14] as

$$
\begin{aligned}
& u_{i}(x, y, z)=u_{i}^{0}(x, y)+\left(z-z_{i}\right) \psi_{x i}(x, y) \\
& v_{i}(x, y, z)=v_{i}^{0}(x, y)+\left(z-z_{i}\right) \psi_{y i}(x, y) \\
& w_{i}(x, y, z)=w_{i}^{0}(x, y),
\end{aligned}
$$

where $u_{i}$ and $v_{\mathrm{i}}$ refer to the in-plane displacements; $w_{i}$ refers to the transverse displacements through the thickness of the $i$-th plate element; $u_{i}^{0}, v_{i}^{0}, w_{i}^{0}$ are the displacements at the midsurface of the $i$-th plate element, respectively; and $\psi_{x i}(x, y), \psi_{y i}(x, y)$ denote rotations of transverse normals about $x$ and $y$ axis, respectively.

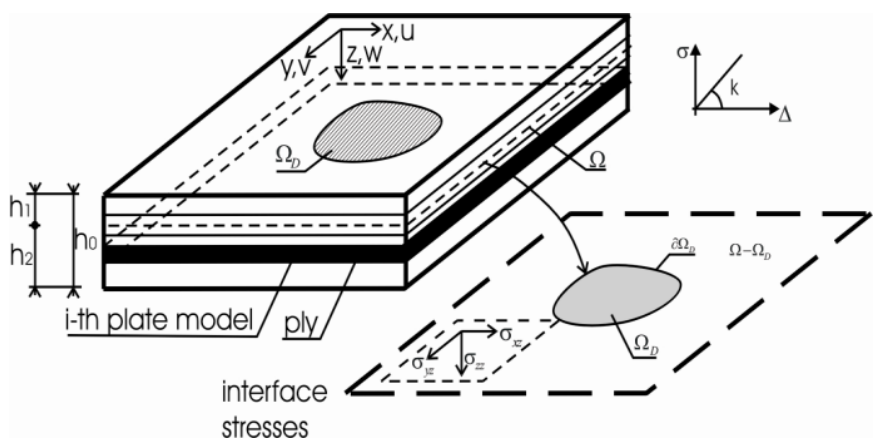

Fig. 3. Mechanics of a delaminated composite structure.

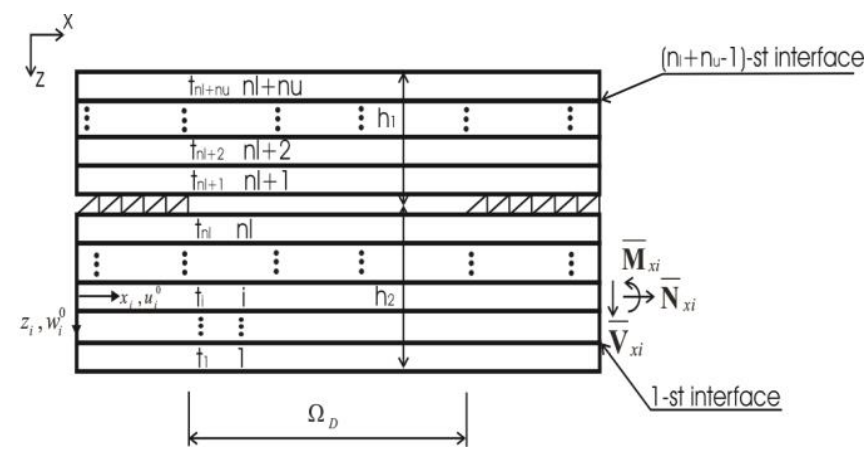

Fig. 4. Laminate subdivision in plate elements.

At the reference surfaces, the membrane strain vector $\varepsilon$, the curvature $k$, and the transverse shear strain $\gamma$, respectively, are defined as:

$$
\begin{gathered}
\left\{\begin{array}{c}
\varepsilon_{x i} \\
\varepsilon_{y i} \\
\gamma_{x y i}
\end{array}\right\}=\left\{\begin{array}{c}
\frac{\partial u_{i}^{0}}{\partial x}+\left(z-z_{i}\right) \frac{\partial \psi_{x i}}{\partial x} \\
\frac{\partial \mathrm{v}_{i}^{0}}{\partial y}+\left(z-z_{i}\right) \frac{\partial \psi_{y i}}{\partial y} \\
\frac{\partial u_{i}^{0}}{\partial y}+\frac{\partial \mathrm{v}_{i}^{0}}{\partial x}+\left(z-z_{i}\right)\left(\frac{\partial \psi_{x i}}{\partial y}+\frac{\partial \psi_{y i}}{\partial x}\right)
\end{array}\right\} \\
\left\{\begin{array}{c}
\kappa_{x i} \\
\kappa_{y i} \\
\kappa_{x y i}
\end{array}\right\}=\left\{\begin{array}{c}
\frac{\partial \psi_{x i}^{0}}{\partial x} \\
\frac{\partial \psi_{y i}^{0}}{\partial y} \\
\frac{\partial \psi_{x i}^{0}}{\partial y}+\frac{\partial \psi_{y i}^{0}}{\partial x}
\end{array}\right\},\left\{\begin{array}{l}
\gamma_{y z i} \\
\gamma_{x z i}
\end{array}\right\}=\left\{\begin{array}{l}
\psi_{x i}^{0}+\frac{\partial w_{i}^{0}}{\partial y} \\
\psi_{x i}^{0}+\frac{\partial w_{i}^{0}}{\partial x}
\end{array}\right\} .
\end{gathered} .
$$

In this work, standard FSDT finite elements available in ANSYS software are used. These elements are joined at the interfaces inside each sub-laminate using coupling elements (CE) or rigid links characterized by two nodes and three degrees of freedom at each node [14].

The constitutive equation of the interface involves two stiffness parameters, $k_{z}$ and $k_{x y}$, imposing displacement continuity in the thickness and in-plane directions, respectively, by treating them as penalty parameters. The relationship between the components of the traction vector $\sigma=\left[\sigma_{z x}, \sigma_{z y}, \sigma_{z z}\right]^{T}$ acting at the lower surface of the upper sublaminate, in the in-plane ( $x$ and $y$ ) directions and in the out-of-plane one $(z)$, respectively, and the corresponding components of the relative interface displacement vector $\Delta=[\Delta u, \Delta v, \Delta w]^{T}$ are expressed in matrix form as [3], [14]:

$$
\sigma=K \Delta
$$

$$
\left(\begin{array}{l}
\sigma_{z x} \\
\sigma_{z y} \\
\sigma_{z z}
\end{array}\right)=\left(\begin{array}{ccc}
k_{x y} & 0 & 0 \\
0 & k_{x y} & 0 \\
0 & 0 & k_{z}
\end{array}\right)\left(\begin{array}{c}
\Delta u \\
\Delta v \\
\Delta w
\end{array}\right),
$$

where $K$ is the diagonal matrix of stiffness parameters $k_{x y}$ and $k_{z}$.

The interface elements are implemented using the COMBIN14 type element. The relative opening and sliding displacements are evaluated as the difference between displacements at the interface between the lower and upper sublaminate. In order to avoid interpenetration between delaminated sublaminates in the delaminated region $\Omega_{D}$, a unilateral frictionless contact interface can be introduced, characterized by zero stiffness for opening relative displacements $(\Delta w \geq 0)$ and a positive stiffness for closing relative displacements $(\Delta w \leq 0)$; then the contact stress $\sigma_{z z}$ is $[3,14]$

$$
\sigma_{z z}=\frac{1}{2}(1-\operatorname{sign}(\Delta w)) k_{z} \Delta w
$$


where $k_{z}$ is the penalty number imposing contact constraint, and sign is the signum function. A very large value of $k_{z}$ restricts sublaminate overlapping and simulates the contact condition. This element is a unidirectional element with nonlinear constitutive relationships with appropriate specialization of the linear constitutive law according to (36).

If we introduce a scalar damage variable $D$ with the value of 1 for no adhesion and the value of 0 for perfect adhesion, we get a single extended interface model with constitutive law valid both for undelaminated $\Omega-\Omega_{D}$ and delaminated $\Omega_{D}$ areas. Consequently, the constitutive law can be expressed as

$$
\sigma=(1-D) K \Delta
$$

In order to determine the individual ERR, the relative interface displacements must be expressed in the local coordinate system attached to the delamination front shown in Fig. 5. Denoting the unit vectors in the normal and tangential directions to the delamination front as $n$ and $t$, respectively, the relative interface displacement in the global $x, y, z$ system $\{\Delta\}=\{\Delta u, \Delta v, \Delta w\}^{T}$, is related to that in the $n, t, z$ system $\{\Delta\}=\left\{\Delta u_{n}, \Delta u_{t}, \Delta w\right\}^{T}$ by transformation matrix of direction cosines.

The problem of ERR computation can be solved locally by using interface variables, that is interlaminar stresses and relative variables. The connection between the interface approach and fracture mechanics approach will be established, demonstrating that the interface approach corresponds to the limit physical situation when the thickness of a thin adhesive layer tends to zero. Using the interface constitutive equation (36) to compute interlaminar stresses, leads to the following total ERR expression for unilateral contact conditions:

$$
G=\frac{1}{2} \lim _{k_{z}, k_{x y} \rightarrow \infty}\left[k_{z} \Delta w^{2}+k_{x y} \Delta u^{2}+k_{x y} \Delta v^{2}\right], \quad \Delta w \geq 0 ，
$$

where $G$ is the local ERR function along the delamination front.

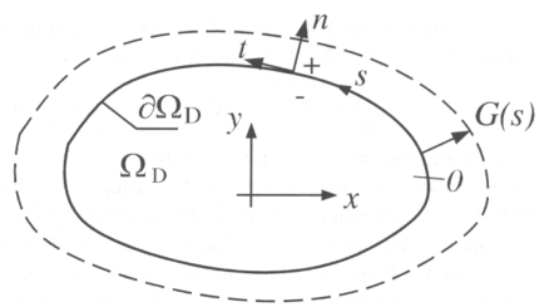

Fig. 5. Propagation of delamination front [3].

In order to predict crack propagation in laminates for general loading conditions, ERR distributions along the delamination front are needed. Fracture mechanics assumes that delamination propagation is controlled by the critical ERR. Delamination grows on the region of the delamination front where the following condition is satisfied and is in the form of [3]

$$
\left(\frac{G_{I}(s)}{G_{I}^{c}}\right)^{\alpha}+\left(\frac{G_{I I}(s)}{G_{I I}^{c}}\right)^{\beta}+\left(\frac{G_{I I I}(s)}{G_{I I I}^{c}}\right)^{\gamma} \geq 1,
$$

where $\alpha, \beta$ and $\gamma$ are mixed-mode fracture parameters determined by fitting experimental test results.

In this paper, standard First-Order Deformation Theory (FSDT) finite elements available in ANSYS software are used. These elements are joined at the interfaces inside each sublaminate using coupling elements (CE) or rigid links characterized by two nodes and three degrees of freedom at each node.

The FE model of the plates adjacent to the delamination plane in proximity of the delamination front is illustrated in Fig. 6.

The extent of the propagation of the delamination area can be established by realizing in which the relation (38) is first satisfied, leading to modification of the delamination front. Therefore, the delamination growth analysis must be accomplished iteratively.

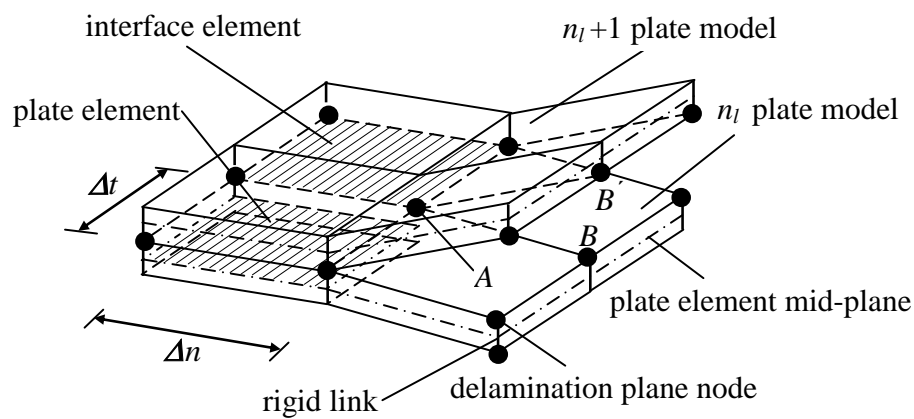

Fig. 6. Detail of FE model in proximity of the delamination front [3]

ERR are computed by using [3]:

$$
\begin{aligned}
G_{I}(A) & =\frac{1}{2} \frac{R_{A}^{z} \Delta w_{B-B^{\prime}}}{\Delta_{n} \Delta} \\
G_{I I}(A) & =\frac{1}{2} \frac{R_{A}^{n} \Delta u_{n B-B^{\prime}}}{\Delta_{n} \Delta} \\
G_{I I I}(A) & =\frac{1}{2} \frac{R_{A}^{t} \Delta u_{t B-B^{\prime}}}{\Delta_{n} \Delta_{t}},
\end{aligned}
$$

where $R_{A}^{z}, R_{A}^{n}, R_{A}^{t}$ are the reactions in the spring element connecting node $A$ in the $z$, normal and tangential direction to the delamination front; $\Delta w_{B-B^{\prime}}, \Delta u_{n B-B^{\prime}}, \Delta u_{t B-B^{\prime}}$ are the relative $z$, $n, t$ displacements between the nodes $B$ and $B^{\prime}$ located immediately ahead of the delamination front along its normal directions passing through $A ; \Delta_{t}$ and $\Delta_{n}$ are the characteristic mesh sizes in the normal and tangential directions [3], [14].

\section{THE EXAMPLE OF DAMAGE MODELING}

Using ANSYS, a sandwich plate (1-2 model) comprising two sub-plates of thicknesses $t_{1}=h_{1}=0.5 \mathrm{~mm}$ and $t_{2}=h_{2}+$ $h_{3}=10.5 \mathrm{~mm}$ is analyzed. The sub-plates are loaded by the load mode I $(F=1 \mathrm{~N} / \mathrm{mm})$. Dimensions of the sandwich plate are shown in Fig. 7. 

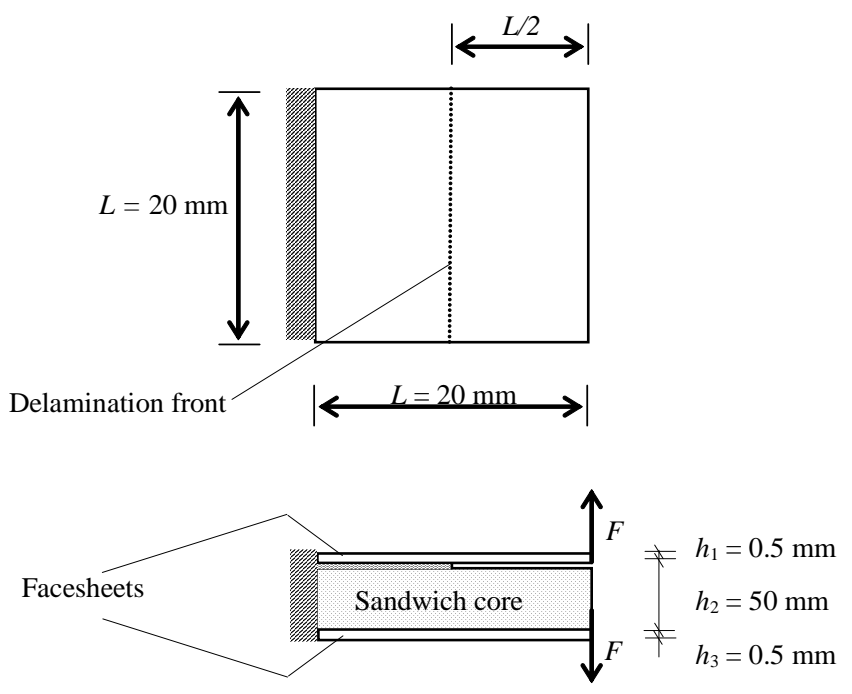

Fig. 7. Sandwich geometry.

The sheets are made of carbon/epoxy composite with fiber volume fraction $\xi=0.6$.

The mechanical characteristics of the core:

$$
\begin{aligned}
& E_{x}=E_{y}=E_{z}=0.4 \mathrm{GPa} ; \\
& G_{y z}=G_{x y}=G_{x z}=0.02 \mathrm{GPa} ; \\
& v_{\mathrm{xy}}=v_{\mathrm{xz}}=v_{\mathrm{yz}}=0.4 .
\end{aligned}
$$

The stiffness of the spring elements binding the subplates is chosen as $k_{z}=k_{x y}=10^{8} \mathrm{~N} / \mathrm{mm}^{3}$. The interface between the subplates is modeled without stiffness for opening displacements and with positive stiffness for closing displacements.

The response mode of components of displacements, energy release rate and spring reaction forces along the delamination front is calculated.

\section{CONCLUSION}

A two-subplate sandwich FEM [17]-[21] model which incorporates interface models based on fracture and contact mechanics has been proposed. The interface between sublaminates is modeled by CE. The delamination front is created by spring elements COMBIN14, in each node of the delamination front by three elements. The sub-plates were modeled by using shear deformable elements SHELL181 in the program ANSYS.

Contour plots of displacements in $y, z$ and $x$ directions are shown in Figs 8-10, respectively.

The individual components of the spring reaction force, displacements and ERR for response modes I, II and III along the delamination front were calculated.

The spring reaction forces $R_{z}$ and $R_{x}$ along the delamination front are shown in Figs 11 and 12, respectively.

The ERR I and ERR II along the delamination front are shown in Figs 13 and 14, respectively.

The results have shown that the response mode $\mathrm{I}$ is predominant and the mode III is negligible.

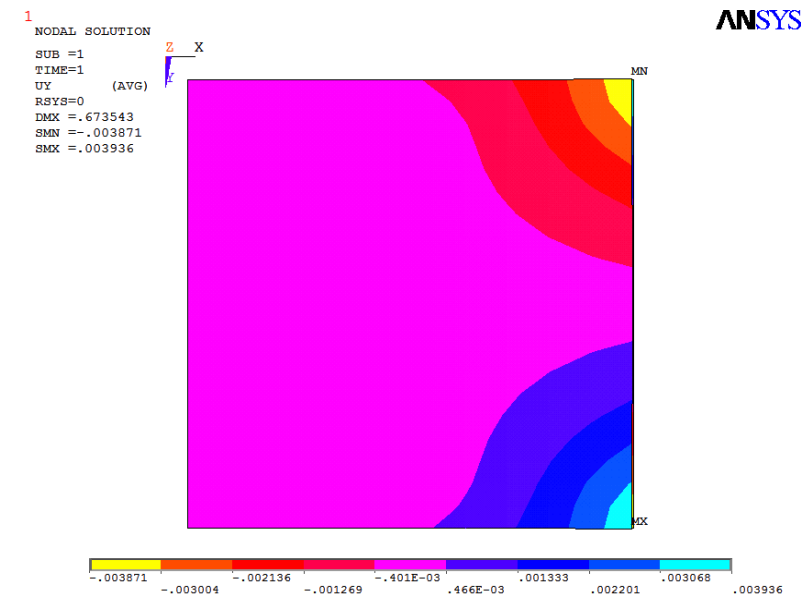

Fig. 8. Displacements in $y$ direction, respectively.

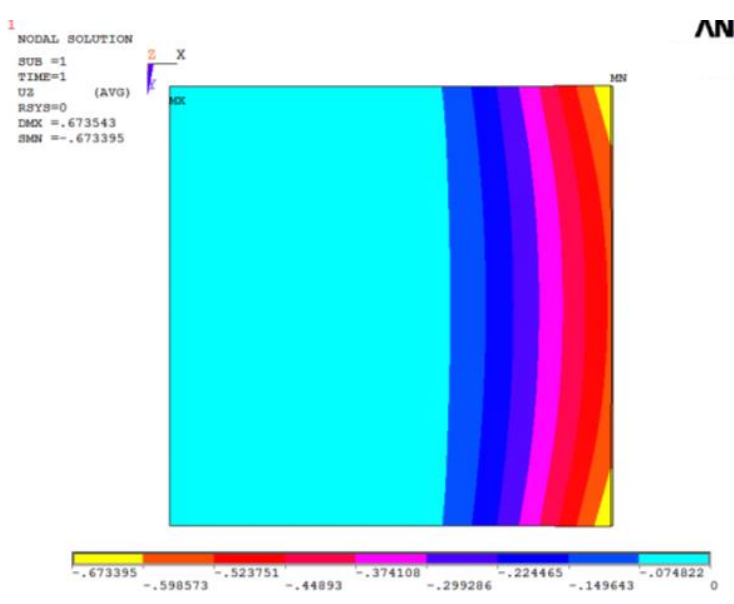

Fig. 9. Displacements in $z$ direction, respectively.

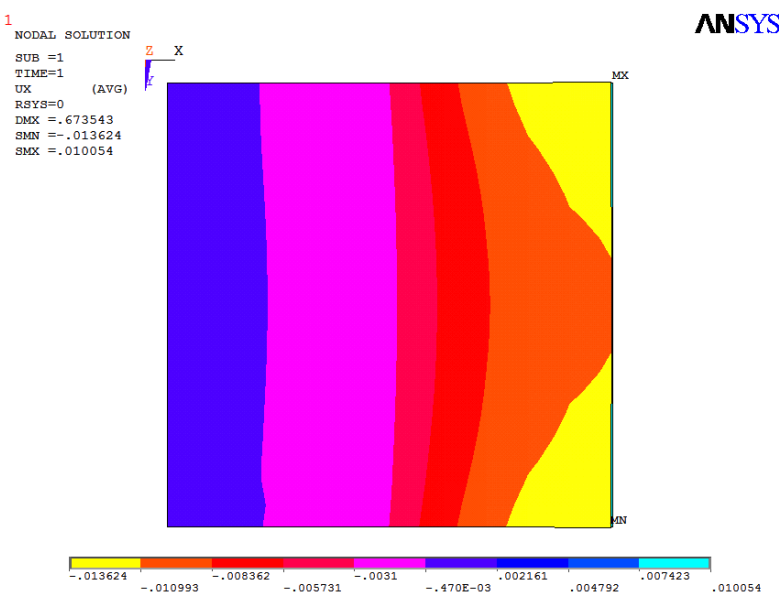

Fig. 10. Displacements in $x$ direction, respectively. 


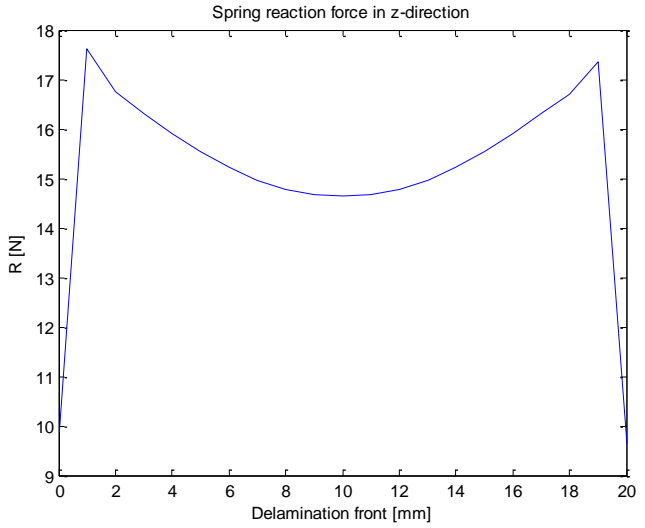

Fig. 11. Spring reaction force $R_{z}$.

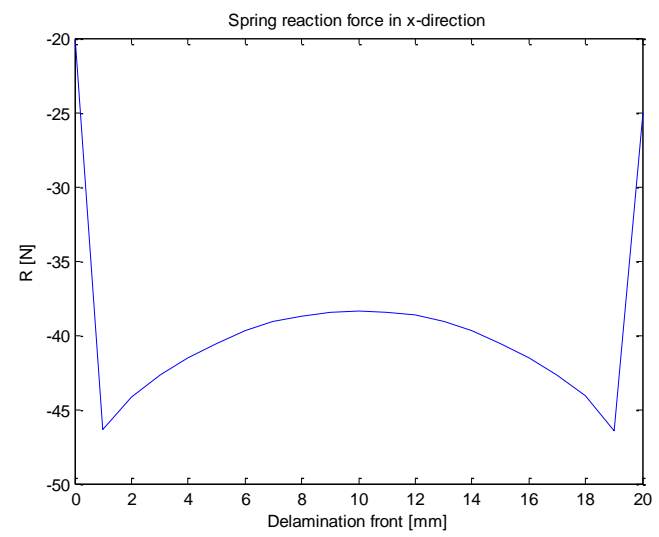

Fig. 12. Spring reaction force $R_{x}$.

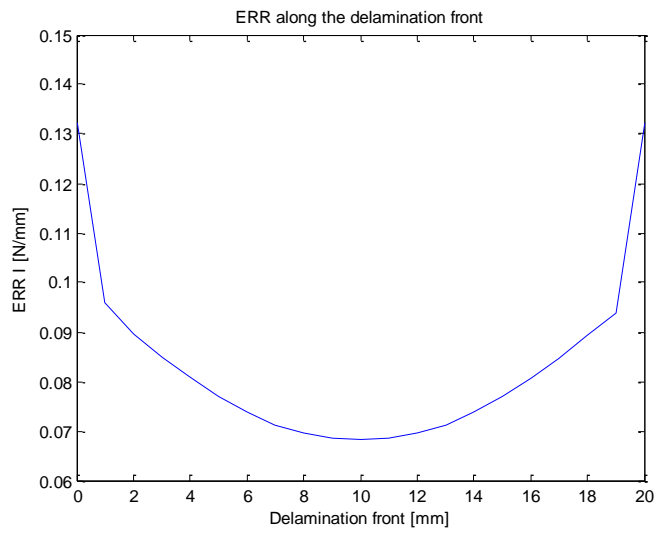

Fig. 13. ERR I.

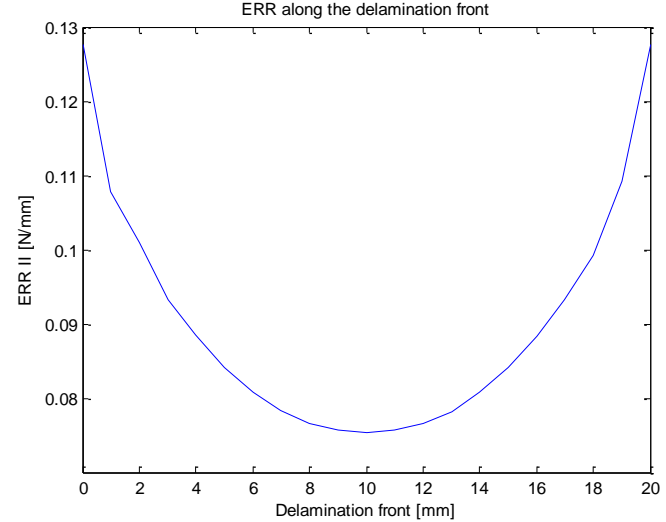

Fig. 14. ERR II.

\section{ACKNOWLEDGMENT}

This paper has been supported by the project VEGA 1/0477/15 "Progressive methods for the solution of structural elements made of composite and other new-age materials".

\section{REFERENCES}

[1] Schoeppner, G.A., Pagano, N.J., "Stress Fields and Energy Release Rates in Cross-ply Laminates," International Journal of Solids and Structures, vol. 11, pp. 1025-1055, 1998. http://dx.doi.org/10.1016/S0020-7683(97)00107-8

[2] Sun, C.T., Manoharan, M.G., "Strain Energy Release Rates of an Interfacial Crack Between Two Orthotropic Solids," Journal of Composite Materials, vol. 23, pp. 460-478, 1989. http://dx.doi.org/10.1177/002199838902300503

[3] E. J. Barbero, Finite element analysis of composite materials, CRC Press, USA, ISBN-13: 978-1-4200-5433-0, 2007.

[4] J. Sykora, M. Sejnoha, J. Sejnoha, "Homogenization of coupled heat and moisture transport in masonry structures including interfaces," Applied Mathematics and Computation, vol. 219 (13), pp. 7275-7285, 2013. http://dx.doi.org/10.1016/j.amc.2011.02.050

[5] S. Harabinova, E. Panulinova, "Properties of Aggregates of SteelMaking Slag," GeoConference on Energy and Clean Technologies: conference proceedings, Albena, Bulgaria - Sofia, vol. 2, 2014, pp. 199202. http://dx.doi.org/10.5593/SGEM2014/B42/S18.026

[6] J. Ma, S. Sahraee, P. Wriggers, L. De Lorenzis, "Stochastic multiscale homogenization analysis of heterogeneous materials under finite deformations with full uncertainty in the microstructure," Computational Mechanics, vol. 55, Issue 5, 25 May 2015, pp. 819-835. http://dx.doi.org/10.1007/s00466-015-1136-3

[7] C. Maruccio, L. De Lorenzis, L. Persano, D. Pisignano, "Computational homogenization of fibrous piezoelectric materials," Computational Mechanics, vol. 55, Issue 5, 8 April 2015, pp. 983-998. http://dx.doi.org/10.1007/s00466-015-1147-0

[8] M. Sejnoha, J. Zeman, "Micromechanical modeling of imperfect textile composites," International Journal of Engineering Science, vol. 46 (6), pp. 513-526, 2008. http://dx.doi.org/10.1016/j.ijengsci.2008.01.006

[9] H. Altenbach, J. Altenbach, W., Kissing, Structural analysis of laminate and sandwich beams and plates, Lublin, 2001.

[10] Z. Gürdal, R.T. Haftka, P. Hajela, Design and Optimization of Laminated Composite Materials, J. Wiley \& Sons, 1999.

[11] R. Dhabale, V. S. Jatti, "Optimization of material removal rate of $\mathrm{AlMg} 1 \mathrm{SiCu}$ in turning operation using genetic algorithm," WSEAS Transactions on Applied and Theoretical Mechanics, vol. 10, pp. 95$101,2015$.

[12] E. Kormanikova, I. Mamuzic, "Buckling analysis of a laminate plate," Metalurgija, vol. 47, no. 2, pp. 129-132, 2008. ISSN 0543-5846.

[13] M. Mihalikova et al., "Influence of strain rate on automotive steel sheet breaking," Chemické listy. vol. 105, no. 17, pp. 836-837, 2011. ISSN 0009-2770. 
[14] M. Žmindák, V. Dekýš and P. Novák. "Fracture mechanics approach for analysis of delamination in composite plates," Advanced Material Research vol. 969, pp. 176-181, 2014. http://dx.doi.org/10.4028/www.scientific.net/AMR.969.176

[15] J. Kralik, "Optimal design of npp containment protection against fuel container drop," Advanced Materials Research, vol. 688, pp. 213-221, 2013. http://dx.doi.org/10.4028/www.scientific.net/AMR.688.213

[16] E. Kormanikova, I. Mamuzic, "Optimization of laminates subjected to failure criterion," Metalurgija, vol. 50 (1), pp. 41-44, 2011.

[17] J. Melcer, G. Lajcakova, "Comparison of finite element and classical computing models of reinforcement pavement," Advanced Materials Research, vol. 969, pp. 85-88, 2014. http://dx.doi.org/10.4028/www.scientific.net/AMR.969.85

[18] J. Yan, "Finite element analysis on steel-concrete-steel sandwich beams," Materials and Structures, vol. 48 (6), 2015, pp. 1645-1667. http://dx.doi.org/10.1617/s11527-014-0261-3

[19] E. Carrera, "Theories and finite elements for multilayered, anisotropic, composite plates and shells," Archives of Computational Methods in Engineering, vol. 9 (2), pp 87-140, 2002. http://dx.doi.org/10.1007/BF02736649

[20] I. Száva, M. Šejnoha, E. Kormaníková et al., Selected Chapters of Mechanics of Composite Materials III. Derc Publishing House, 2013.

[21] C. G. Davila, P. P. Camanho, C. A. Rose, "Failure criteria for FRP laminates," Journal of Composite Materials, vol. 39 (4), pp. 323-345, 2005. http://dx.doi.org/10.1177/0021998305046452

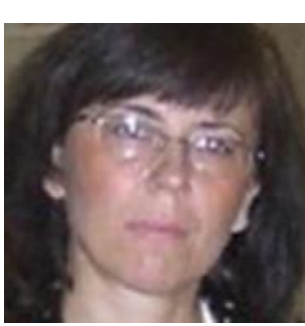

Eva Kormanikova graduated from the study program in building construction at the Civil Engineering Faculty of the Technical University of Košice. After graduation, she started working as an Assistant at the Department of Structural Mechanics of the same Faculty and University. Later, she received the Ph.D. degree in applied mechanics from the Faculty of Mechanical Engineering of the Technical University of Košice. Since 2009, she is an Associate Professor of the Theory and Design of Engineering Structures at the Civil Engineering Faculty of the Technical University of Košice. Her research topic is design and optimization of structural elements and structures made of composite materials.

E-mail: eva.kormanikova@tuke.sk 